\title{
The crisis of COVID-19 and opportunities for reimagining education
}

\section{Crain Soudien}

Centre for Non-Racialism and Democracy, Nelson Mandela University, Gqeberha, South Africa

crain.soudien@uct.ac.za

https://orcid.org/0000-0001-8821-5839

\section{Jaqueline Harvey}

Inclusive Economic Development Research Programme, Human Sciences Research Council, Durban, South Africa

jharvey@hsrc.ac.za

https://orcid.org/0000-0003-3020-1842

(Received: 16 July 2021; accepted: 20 October 2021)

\section{Abstract}

Our argument in this brief contribution is that COVID-19 has brought the experience of education to a crisis with respect to its practices and the theories that inform it. The practice crisis is about the glaring inequalities in peoples' access to education. The theory crisis is about how we learn. Our contention is that our dominant cohort learning approaches fail to address the many differences children bring to the learning task. In response we make two key moves: the first is to restore the centrality of cognition in all processes of teaching and learning, and the second is to situate cognition in its full biopsychosocial complexity. With respect to the first move we begin our discussion of teaching and learning with a focus on cognition and particularly on its executive function component. We provide the explanation of what it is, and with that, we move to our second to show the importance of new learnings about epigenetics that explain the significance of the relationship between the biological and the social to the cognitive process.

Keywords: COVID-19, executive functioning, learning, cognition, inequality, cohort learning

\section{Introduction}

In the build-up to the Yalta conference to discuss the post-World War II reorganisation of Germany and Europe in February 1945, Britain's leading 20th century politician, Winston Churchill, introduced to the world, in his own inimitable way, the expression "Never let a good crisis go to waste." Clichéd in the context of COVID-19 as the expression has become, 
we take seriously its insight that crises force societies to examine themselves. In this short contribution, in the context of COVID-19's unprecedented disruption of teaching and learning around the world, we seek to contribute to the effort of re-examining ourselves in education. We start with the premise that COVID-19 has brought the world of education, as it has to that of health, to a complex crisis with respect to its practices and the theories that inform it. The practice crisis is essentially that of the glaring inequalities in the material realities of communities around the world (see Saavedra, 2020; The United Nations Educational, Scientific and Cultural Organization (UNESCO), 2020). The theory crisis is less well understood and explicated. It has to do with what schools, teachers, learners and households, parents and caregivers in the main, encountered in the experience of dealing with what they thought was the apparently straightforward and well-understood task of managing the task of learning. Challenged by having to mediate ideas, concepts, and information in meaningful ways for their children, they came to realise that the task of learning is complex and that each child requires a distinct learning plan. The value of the crisis, we argue, is that for the first time in almost the whole of the history of mass education, stakeholders in the learning process intuited that new approaches needed to be developed for facilitating the making of deeply just and equitable learning regimes, methodologies, styles, and practices. Our appeal in this contribution is that we not let the moment go to waste. It is an opportunity to rethink mass education. We have begun developing, elsewhere, a set of arguments for the attainment of socially just education (see Soudien \& Harvey, 2020; Soudien et al., forthcoming; Soudien et al., 2021). Here we seek to extend those arguments. What, in the wake of COVID-19, we ask, does a socially just approach to education constitute for the management of the teaching and learning experience?

The heart of our argument is the contention that the core activities of the educational experience - teaching and learning - if they are to be socially just, need urgent revitalisation. COVID-19 provides us with an important opportunity to clarify why and how this might happen at the many levels at which teaching and learning find expression. In Soudien and Harvey (2020), we drew attention to the problem inherent in our dominant approaches to learning. We argue here that COVID-19 has not only emphasized the nature of this problem but has brought it into stark relief. It has shown the inadequacies and blind-spots as well as the culs-de-sac to which our dominant approaches to teaching and learning have brought us. While these approaches, we acknowledge, have been attentive to important dimensions and facets of the issues and problems that arise in teaching and learning they have not, first, focused sufficiently on teaching and learning as primarily cognitive phenomena, and second, to bring us to the thematic focus of this special issue, led to an adequate comprehension of the intersectional nature of the processes surrounding teaching and learning.

In this contribution we make two key moves: we restore the centrality of cognition in all processes of teaching and learning, and we situate cognition in its full biopsychosocial complexity.

With respect to the first move we begin our discussion of teaching and learning, quite simply, with a focus on cognition. We pay particular attention to its executive function component. 
We provide the explanation of what it is, and acknowledge that, it is, of course, relatively well-known, but we add to this the new learnings that we have acquired in the field of epigenetics about the relationship of social factors to the cognitive process. While we anticipate that this work will ultimately hold value for pedagogy, for what teachers do, and for curricula, we focus here on the theoretical issues that are before us in this crisis rather than on those pertaining to practice.

With respect to the second move, our point of departure is that most discussions of teaching and learning have effectively essentialised intersectionality as a largely social phenomenon. We attempt here to explore intersectionality in its full capaciousness, and we seek to bring the psychological and the biological to whatever social dynamics are made of the units of analysis of teaching and learning experiences however they are identified and interpreted. To that end we offer an exploratory model for understanding cognition as an intersectional phenomenon; we make the argument that while conventional explanations of intersectionality are important for understanding teaching and learning processes, explanations of how these processes work cannot depend only on abstracted social analysis. Important as that analysis is, it risks losing sight of how, for learning - the focus of our contribution-cognitive processes work in the brains and bodies of learning subjects. This is the great weakness in many of our contemporary explanations of teaching and learning. These often fail, first of all, to put cognition at the centre of their approaches, and, if they do, they build their analyses around mono-categorical framings of the teaching and learning experience. Educational psychologists tend to have in mind an abstracted brain generalised and universalised to the point of near irrelevance. Sociologists of education, for their part, work with downstream effects, race, class, gender and more that explain all the accompanying realities to the teaching and learning experience but have few resources to comprehend the experience itself.

We argue here that an intersectional explanation of teaching and learning has to have cognition at its centre. Our point, to repeat ourselves, is that if we are to deepen our comprehension and analysis of how our children are learning, we have to find ways of making cognition our major unit of analysis. Of course, we can continue, as sociologists, to look at class, race, and gender, but we must articulate clearly that these factors are not about teaching and learning in and of themselves. They illuminate the questions of teaching and learning but are not the actual phenomena itself. We come to this insistence with the understanding that sense-making is central. It is fundamental to how human subjects learn. Of course, learning is contingent on socially determined factors. One's social background, however one wishes to describe it, matters. But (and this is in some ways our major point) so is one's biology and one's psychological make-up. In arriving at this point we do not wish to revisit the old nature-versus-nurture dichotomy. We dispense with this debate by taking the expanded intersectional view here that at stake in teaching and learning are both nature and nurture. Building on our discussion of cognition, we move on to discuss intersectionality and show how an augmented explanation of intersectionality is of value for arriving at a deeper understanding of socially just learning. 


\section{Re-centring cognition in explanations of teaching and learning}

All individuals, regardless of any social description we wish to attach to them, possess the capacity to learn. We are endowed with the ability to learn new skills and concepts throughout our lives. Education depends on this learning capacity. How this capacity is developed, however, and comes to be realised as human agency, in all its wondrous manifestations - to be, to think, to do, to relate and to prosper as a capacitated and, we hope, a fulfilled human being - is dependent on many factors. How these factors come together is what produces the defining outcomes of human beings' lives-great achievement, simply doing what they think is expected of a normal person, or failure. It is this question of how the factors come together that preoccupies us here because in the dynamic of their combination we, as education theorists, have come to emphasise some things and neglect others and, as a result, have developed partial explanations of how learning works.

But to get to the point of determining how learning capacity is shaped - the politics of learning-we need to separate out some of the key concepts that are pertinent to our discussion. If we do not clarify their relation to, or relevance for, our discussion, we could easily misunderstand what is at stake here. An obvious first concept, one that we could easily take for granted but that is utterly essential for understanding what we are trying to do in this essay, is that of good education. What is good education? It is, in any social environment in any part of the world and at any historical time, an education that gives a human being the ability to live in critical harmony with his/her/their ecology, to appreciate and honour that which nurtures their physical and spiritual selves, and to work with, sceptically and constructively, that which diminishes, degrades, and despoils all of life's joint inheritance. It can be described clinically, as Piaget (cited in Brearley \& Hitchfield, 1966, p. x) did, as the human capacity to move beyond superficial observation ". . . in chase of the ever-receding thought, (it) drives it from cover, pursues and tracks it down, till it can seize it, dissect it and lay bare the secret of its composition." It can also be explained in distinctly social terms, as Freire (1973, p. 3) did in Education for critical consciousness, as the ability to

... relate to their world in a critical way. They apprehend the objective data of their reality (as well as the ties that link one datum to another) through reflection ... And in the act of critical perception, men [sic] discover their own temporality.

Transcending a single dimension, they reach back to yesterday, recognize today, and come upon tomorrow.

They develop what Freire called a critical consciousness of the world. Good education, in these terms, is evident in the ability of human beings to comprehend, engage with, and always stand in readiness to transcend their circumstances, whatever they might be. It is, in the language of our current period, post- and de-dominance of any kind.

Piaget drew attention to the mental processes involved in good education, Freire, the social. Important about Piaget, moreover, and taken several steps forward by Vygotsky (see 
Bradbury, 2020), is the location of mental processes in their contextual realities. Education as a mental process depends on the social environment in which a child finds $\mathrm{him} / \mathrm{her} /$ themselves.

A second critical concept is that of cognition. As Flavell's (1977, p. 2) no longer current Cognitive development still usefully explains, general conceptions of cognition tend to restrict it to what are described as the higher mental functionings of the human mind such as "consciousness, intelligence, thinking, imagining, creating, generating plans and strategies, reasoning, inferring, problem solving, conceptualising, classifying and relating, symbolizing, and perhaps fantasizing and dreaming." But, as he said, there is no principled reason to exclude "non-cognitive-sounding things as emotions, personality, aggression and so on." In his work he emphasised the importance of taking an integrated view of how human minds work and thinking, therefore, of human beings as sentient life forms with complex cognitive systems.

A final, almost confounding, concept that needs to be noted here is that of assessment. The point that we have reached in the assessment discussion, wonderfully, is that our education process should yield, as learning outcomes, remembering, understanding, applying, analysing, evaluating, and creating. These constitute what we now refer to as Bloom's Revised taxonomy (see the chapters in Anderson \& Krathwohl, 2001). Powerful about these outcomes is that they represent, as we shall see, the core elements of executive function. Assessment, however, and this is why the concept is confounding for our purposes, is aimed at the outcome of the teaching and learning process. To be sure, these outcomes are reverseengineered by many teachers, encouraged by assessment theorists, to shape and produce deeply cognition-rich experiences for their learners but, to stress the point, it is not part of executive functioning in and of itself. The outcome is different from the process; our interest is in the process.

With these clarifications, we emphasize that our point of departure, like Flavell's, now fifty years later, is to focus on particular aspects of cognition. The aspect that concerns us here is that of executive functioning, or, simply, executive function. Executive function includes higher order processes-working memory, inhibitory control, and cognitive flexibility - that enable complex decision-making goal-directed behaviour, and the development of key cognitive and socioemotional skills (Ibrahimet al., 2017; Ji \& Wang, 2018; Logue \& Gould, 2014). Executive function refers, essentially, to the psychological processes that consciously control thought and action (Zelazo \& Müller, 2011). The depth and breadth of literature regarding executive function is immense, but the requirements of this publication constrain us to focus this presentation in a particular way. We thus refer to executive function in a general sense. We are sensitive, as we shall show below, to how executive function works in the context of other features of human beings' mental make-up, their wellbeing, and, therefore, their susceptibility to happiness, depression, distress and so on. Our interest, however, is in how human beings function in relation to the processes involved in the development of their education. 
We come to this interest understanding that the idea of executive function has a long and distinguished research history. It came into prominence in the 1970s and is now recognized as central to thinking about the development of learning (see the collected chapters in Meltzer, 2007). It is central to the learning process. It can, moreover, be shaped and steered. Its framework of reference, however, has been largely clinical with a focus on the learning challenges of the individual learner and the consequence of producing a psychology of learning that is asocial. Our intention here is to take executive function into a larger analytic frame in which we bring into play the biological, the psychological, and the social. A recent contribution by Meltzer and Greschler (2018, para. 22), interestingly, roots its significance in the social environment of the school and the family. They noted,

When teachers and parents build an executive function culture in their classrooms and their homes, they empower children to learn how to learn and problem-solve flexibly. When schools and families foster effort, persistence, and executive function strategies, students develop self-confidence, resilience, and a strong work ethic, the gateways to academic and life success in our 21 st century world.

Social as the inputting factors and the spaces of enactment of executive function are in Meltzer and Greschler's plea, there is little in their discursive framing of the concept that suggests that it could be placed in a larger analytic. The general literature, too, it should be noted, shows little awareness of such a possibility.

To activate a larger analytic, we begin with the assertion that all individuals, as human subjects, must be able to adapt to their changing environments. COVID-19 has been an environmental change of great magnitude. It has forced us to adapt and demonstrates, now, the need for adaptation. It has come to underline the importance of understanding executive function better. The ability to adapt through goal-directed behaviour and regulation of reflexive reactions is based on executive function (Ji \& Wang, 2018; Logue \& Gould, 2014). A key marker of successful education is thus the development of cognitive and executive functions in what we term cognitively resourceful individuals. These individuals have the capacity for lifelong learning and adaptability and are, furthermore, motivated to develop their individual capabilities. A meta-analysis of studies of the relationship between executive functioning and academic performance by Cortes Pascual et al. (2019, para. 10) found executive function "to be more significant for academic performance than the intelligence quotient, the variable traditionally considered to be the best predictor of academic success."

\section{Intersectionality between nature and nurture}

Having, we hope, made clear why we are focusing on executive function, it is important now to explain the intersectional approach we take in this contribution. Cognitive functions rely on brain activity that, in turn, is dependent on brain development and neural circuitry (Bueno, 2021). Therefore, to explain how cognitive capabilities are developed, and more specifically executive function, we need to consider child development and, in particular, the intersectionality of the biological and the social. Advances in the biological, developmental 
neuroscientific, epigenetic, and social sciences have provided key insights into the process of healthy development and into how it can be disrupted, and how it can be supported. We now understand that both genetic and environmental experiences interact at many levels to influence child development (Shonkoff, 2010). Gene-environment interplay ( $\mathrm{G} \times \mathrm{E}$ interplay) reflects a reciprocal relationship between an individual's genetic endowment and his/her/their environment (Anreiter et al., 2017). Children are not born as blank slates, but instead have a genetic blueprint as an initial framework for development. Many environmental factors then act as influences to enable children to fully develop their capabilities (Bueno, 2019; National Scientific Council on the Developing Child, 2020; Shonkoff, 2010). All biological systems develop in this way, including the brain and, therefore, the cognitive, social, and emotional capacities required for learning and success. Importantly, the physiological basis of executive function is the prefrontal cortex in the brain and neural connectivity between this region and other brain areas is crucial to executive function (Li \& Wang, 2018); healthy development is thus of great significance.

The foundations of brain architecture are built in the early years of a child's life and are shaped by interactions between genes and experiences in an environment of relationships over time (Fox et al., 2010; National Scientific Council on the Developing Child, 2020). During these early years of development, the extreme adaptability of the brain enables it to respond to environmental factors, be they positive or negative influences. This is thus a period of both enormous opportunity but equally sizable vulnerability. When his/her/their environment includes supportive responsive relationships and adequate resources, a child's well-functioning development is more likely. However, environments characterised by hardships or adversity, such as living in poverty, disrupt the development of multiple biological systems (Knudsen, et al., 2006; National Scientific Council on the Developing Child, 2020; Shonkoff \& Bales, 2011). This can initiate a cascade of negative outcomes across the life span, including inadequate school readiness, lowered academic performance and socio-emotional development, decreased tertiary education completion, lower economic productivity and earnings, and increased likelihood of crime and ill health (Babcock, 2014; National Scientific Council on the Developing Child, 2020). It is thus crucial that proposed policy and interventions as well as education systems recognise that early experiences influence biological system development, including neural circuitry, with lifelong impacts on learning, behaviour, wellbeing, and health outcomes.

It is not just in early life, however, that life events exert an impact on executive function. Using a sample of 700 university students, Ji and Wang (2018) showed that recent stressful life events had a negative impact on participants' performance on three executive function tasks compared to their peers who had not experienced such events. In contrast, adverse childhood experiences (ACEs) impacted performance on only one task, although this may need further exploration given the diversity of these experiences. ACEs refer to forms of abuse (e.g., domestic violence, sexual abuse), neglect (e.g., emotional neglect, physical neglect), and household dysfunction (e.g., parent divorce, premature death of parent) during childhood that cause harm or distress, negatively impacting the physical or psychological health and development of the child, including executive function (Felitti et al., 1998; Ji \& 
Wang, 2018; Lund et al., 2020). Nevertheless, this indicates that life events, and we show how these can include a spectrum of contexts, from inside the family to the larger social world, have an important influence on executive function. We argue that COVID-19 is one such stressful life event. Johnson et al. (2021) highlighted how the closure of physical educational spaces and the transition to online learning during COVID-19 limited opportunities for face-to-face transactional engagements. These types of interactions are crucial to deep thought and to positive epigenetic changes. Additionally, the closure of these spaces was a source of stress for both instructors and students (Johnson et al., 2021).

Furthermore, in this special issue, Pillay and colleagues explore how the home environment influenced the experience of online learning by female African university students. The authors highlight excellently the role that environmental factors, in this case gender as well as material resource inequities, played in the experiences of the participants. An interesting point made by the authors is that some participants were able to draw inspiration from the strength and determination of prominent female figures in their lives that enabled them to develop resilience. In this situation, while the participants had lost meaningful face-to-face engagements in their educational environment, they had still been able to gain positive influences through other relationships in their home environment. Consideration of executive function in studies such as these can be of immense value.

Gene-environment interplay not only influences brain architecture but is able, furthermore, to affect gene expression (Center on the Developing Child at Harvard University, 2016). Both positive and negative experiences can leave a "chemical signature" on genes (Center on the Developing Child at Harvard University, 2016, p. 8), that influences how easily a gene is expressed without altering the DNA sequence itself. This is referred to as epigenetic adaptation and is the mechanism through which factors within one's environment, such as relationships, resources, and nutrition, influence one's observable traits or phenotypes (Bueno, 2021; Denhardt, 2017; Ibrahim et al., 2017). Epigenetic mechanisms include DNA methylation, histone modifications such as acetylation or methylation of histone tails, or noncoding RNAs such as microRNAs (Ibrahim et al., 2017). This field has provided compelling evidence regarding the influence of the environment on genetic expression and executive function, largely using animal studies that have linked diet and early stressors to epigenetic adaptations and resultant executive function changes (Ibrahim et al., 2017). In terms of studies using human subjects, the systematic review by Ibrahim et al. (2017) provided evidence that epigenetic changes, such as DNA methylation, in response to environmental cues were able to influence executive function, particularly working memory. More recently, Chen et al., (2020) produced the first study to identify genes that interact with parental warmth to influence executive function. This study showed that the interaction between parenting style and the genetic makeup of his/her/their children is able to impact outcomes. Although this is an emerging field and further studies need to be conducted, it has therefore been proposed that early environmental factors influence gene expression that, in turn, impacts executive function (Ibrahim et al., 2017). Examples of environmental factors that have been linked to executive function development include stress, nutrition, relationships with family members, and school education (Denhardt, 2017; Ji \& Wang, 2018; Logue \& Gould, 2014). However, with reference again to the study by Ji and Wang (2018), the effect 
of childhood events on executive function are further influenced by other factors such as social support, personal growth, and environmental changes. A holistic perspective is achieved only when both biological and social factors are considered. Furthermore, it has been indicated that epigenetic markers formed as a result of negative environmental influences can be reversed (see Frías-Lasserre et al., 2018). This has highlighted the potential of providing adequate support, and possibly interventions, in the formal education space to all learners. Important to note at this point is the universality of the experience of biological and social factors in human development; they can arise anywhere. ${ }^{1}$

At this juncture an important characteristic of epigenetic research must be made clear along with a strong cautionary note: epigenetic changes in response to environmental stimuli are not deterministic (Mansfield \& Guthman, 2015). The complexities of the interplay between our biology and our experiences over time do not allow for such a viewpoint. Instead, we must focus on how insight from epigenetic research aids us in understanding individual variation as both biological and social, a constant refinement as we develop. This emphasis moves us towards social justice; it is not the individual and his/her/their genetic material that solely determines their outcomes, but the broader environments in which they live as well. In this sense it is an "anti-racist science" as described by Mansfield and Guthman (2015, p. 4). The caution, however, is that the plasticity of epigenetics - the susceptibility of its chemical variation to environmental influences - makes it akin to eugenics when based on notions of what is normal or optimal, the latter often based on race or class (see Mansfield \& Guthman, 2015). We note this tension in order to position ourselves against it and argue for critical scrutiny of epigenetic research. While we have argued that individuals may require support to achieve their full potential, we do not aim to evaluate differences against an unstated (but often Western) norm and attempt to fix them.

Bearing this in mind, based on the argument we have presented, epigenetic mechanisms and executive function should be core foci in the education system. Slade (2020, para. 9), blogging for the ASCD on their website ASCDINService, emphasized that the most critical skill the most successful American schools and classrooms dealing with the crisis of COVID19 have demonstrated is

a sense of student agency and ownership over their own learning. Trying to replicate a standard, traditional classroom where the teacher is constantly present does not work as we teach and learn remotely ... Students need to develop an understanding of their own role in the learning process and encouraged to see themselves more as agents, or ideally owners of their own learning.

In this situation, wellbeing stands at the very centre of the learning experience. In the context of South Africa, the significance of this is evident in Jansen and O'Ryan's (2020) collection

1 In making this point we are acutely aware of the racial uses to which educational analyses using intelligence quotient tests have been put and the not-quite adequately analysed consequence of that development - an avoidance of questions of biology in discussions of learning (see the collection of chapters in Richardson \& Spears, 1972). Our bodies and our biologies do not carry any racial markers, and, emphatically so, our brains do not. Race is a social construct so there is no such thing as a white brain or a black brain or a European brain or an African brain. 
of stories penned by learners about their lockdown experience. In every other story, learners talk of taking charge of their learning. In evidence is intense executive function. Usman Desai, for example, said, "I encourage every student to start by making a few timetables . . . start by managing your life" (cited in Jansen \& O'Ryan, 2020, p. 70). But they also discover how hard it is to discipline themselves. "Despite this", says 18-year-old Tamar Jansen of her success at having managed to exercise executive functioning in class-to pay attention in class and come to her revision process relatively successfully, "learning under lockdown gave me a good dose of depression and suddenly I realized that this is what I asked for" (p. 76). She wanted school to be cancelled. But she had taken far too much for granted. Sisonke Del Fava had to go through failure to understand better what he needed to do. He explained,

The first day I attempted to do my schoolwork and it became a real struggle — almost every 15 minutes or so I would get up and lose focus. I would even tell myself that I would do my work at night, but when the time came, I would just start making up excuses and would delay for the next day. It is also true when people say the excuses sound best to the ones that make them up. I can relate. On the fourth week of the lockdown, I told myself that I cannot torture myself with negativity and mediocrity, so that is when I decided to read books, seeking for motivation and the drive of productive work ethic and yes, it helped-I wanted to read more. (p. 168)

These young learners discovered the need to develop executive function but realised that it is not something that is just switched on at will; it has to be cultivated. In this, the nature of three environments in which children most often find themselves are crucial: immediate family; community in which they live; and their school. The cultivation of many skills, including executive function, is influenced by the positive and negative stimuli they experience in these environments (Frías-Lasserreet al., 2018). We have listed some influential factors in this contribution, but, largely, these have been in broad terms. For example, we have referred to poverty as a stressful experience. However, there are specific factors that need to be explored. How, for example, does the experience of parental stress from living in poverty influence their parent-child relationship and the child's development? In order to explore these types of questions, we propose the model below as a starting point.

\section{Bringing it all together: Towards a model of how learning works}

Clearly, what is needed to deal with the challenges thrown up by COVID-19 is to understand what is actually happening in the experience of learning and, as Piaget explained (see Brearley \& Hitchfield, 1966), to understand and deconstruct the actual experience. COVID19 has been an extremely challenging and stressful experience for learners in that it carries consequences for their development. As shown in the work of Ji and Wang (2018), stressful events can impact executive function. Already known as crucial psychological functions in the process of learning, we see in the examples of Jansen and O'Ryan's students' narratives illustrations of the centrality of executive function. There is a need to ensure that all learners are provided with enriched environments in which to fully develop their biological capacities. 
But how might we more systematically and analytically approach the teaching and learning experience? How might we understand it more conceptually? As an exploratory foray into a more analytic approach to undertaking research into executive functioning, we provide here the basic foundations of a model (Figure 1) for discussion. This model is based on those developed for other sociobiological interactions by researchers such as Shonkoff et al., (2012), Alvarez et al. (2018), and others. Prominent in the model is the principle of articulation and interaction. We take as a starting point here Patricia Hill Collins's (2019, p. 15) statement that "relationality is an essential core construct for intersectionality itself." Targeted in this approach is what she calls "mono-categorical thinking" (p. 25). The categories in the rapidly developing intersectionality literature are those of race, class, gender, sexuality and all the structural or social forces and registers at work in activating power and the making of difference. This is acknowledged in the model through recognition of individual factors, e.g., gender and race, as well as social and physical factors of their environment, e.g., socioeconomic status and relationships with caregivers. These environmental aspects both independently and jointly impact development. For instance, responsive caregiving is able to act as a buffer against adversity which may otherwise negatively impact development (Alvarez, et al., 2018; Shonkoff, 2010). Another example is the finding that socioeconomic status is significantly associated with brain structure and most cognitive skills, including executive function (Brito \& Noble, 2018; Finders et al., 2012; Tomalski \& Johnson, 2010). The model then takes this a step further. It brings to the array the factor of biology to produce an activating frame within which to hold and make sense of the learning experience-principally, executive function. It brings the biological into conjunction with the social and proposes a frame within which social experiences and environmental factors interact with genetic makeup. The crux of the model lies here where "genetic predisposition moderates the effects of environmental influence and differential sensitivity to context can result in differential outcomes" (Shonkoff, 2010, p. 360. See also Fox et al., 2010 and Wiebe et al., 2009). This dynamic and complex interaction over time or within a critical period of development then results in various physiological adaptations and disruptions that influence lifelong outcomes in learning, behaviour, and health (Shonkoff et al., 2012). For example, our genes determine the formation of brain architecture and neural circuits, but this process is also shaped by experiences, such as children having caregivers who read to them or who engage responsively when their children reach out for interaction. Healthy development of this foundation over the course of early childhood is the basis of higher-level skills such as executive function, an important outcome for learning (Center on the Developing Child at Harvard University, 2016).

In order to adequately develop the potential of all individuals, we argue that South African research needs to consider how the relationship between genes and environment contributes to individualised capacities and outcomes. The model described here is an initial step towards exploring this gap in empirical research, bearing in mind the potential tensions in epigenetic research that we described above. 
Figure 1

The basic foundations for a model.
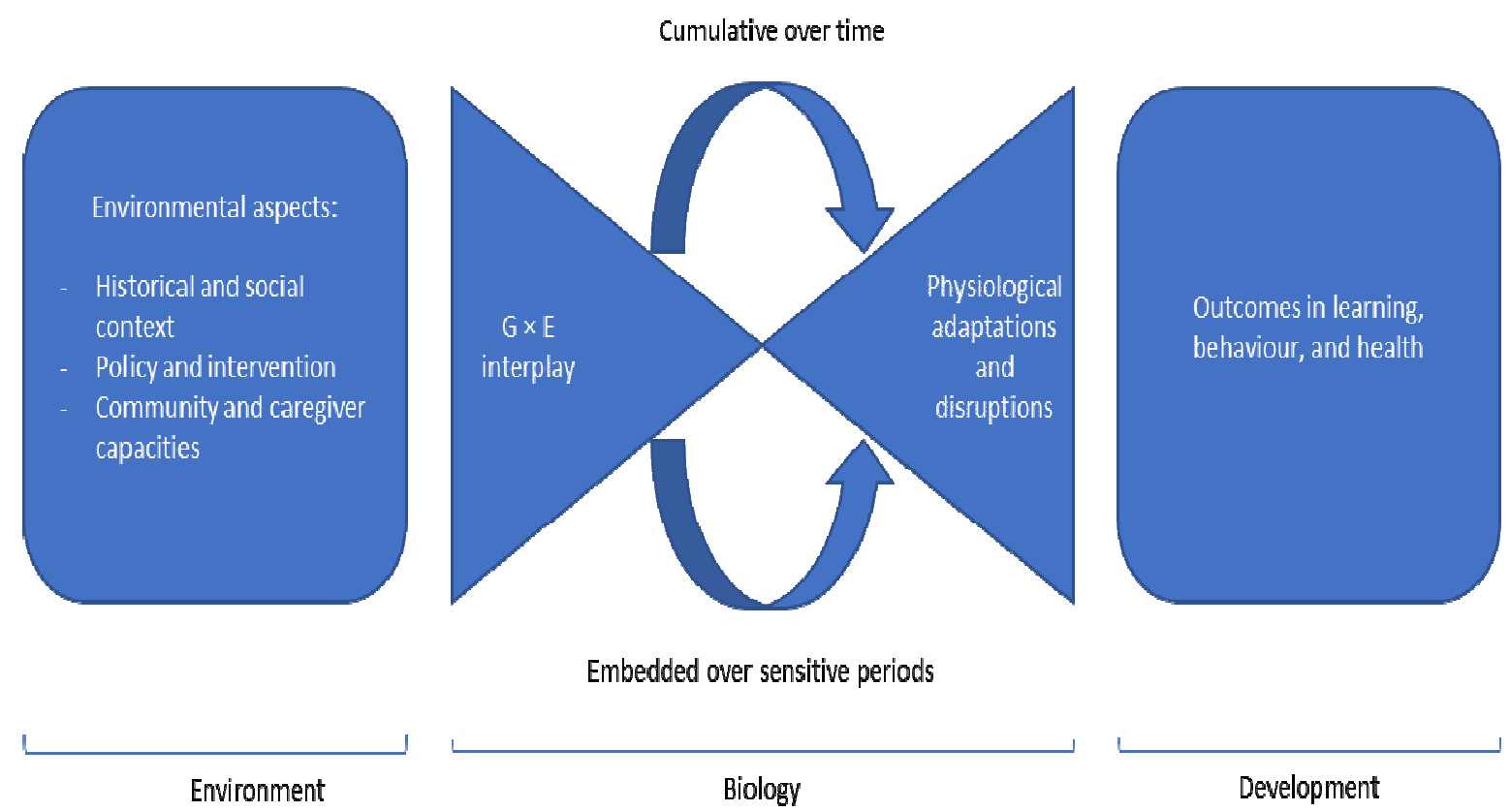

Embedded over sensitive periods

Environment

Biology

Development

Consideration of gene-environment interplay can add valuable insights into individual development and understanding students' responses to the educational environment. Elucidating the relationship between genes and environment can empower teachers to use respectful and flexible teaching practices that act as a positive environmental factor that enables full development of a student's potential (Bueno, 2019). For example, the dynamic complexity of genetic and environmental factors can lead some students to prefer one activity in the classroom, while others may prefer another (Anreiter et al., 2017). Teachers who are able to provide a range of experiences flexibly in their classrooms are better able to embrace this diversity of interests and abilities and support each individual student in reaching their potential (Anreiter et al., 2017; Bueno, 2019). This leads us to a fundamental point: there is a need to forgo a one-size-fits-all approach to learning and develop, instead, educational approaches that maximise each student's potential.

Environments do not operate independently of our genes but rather in conjunction with them. Equally, genes do not operate independently of experience and therefore educationalists need not fear genes as deterministic. Indeed, teachers should think of themselves as drawing out a child's genetic potential rather than writing haphazardly on a mythical blank slate. (Ashbury \& Plomin, 2014, p. 145)

It is thus important to acknowledge that genes are responsive to the environment and that, given this interplay, all individuals are unique in their outcomes. COVID-19 has highlighted this for us. We argue that there must be a move away from cohort learning and, instead, the embracing of more flexible teaching approaches. The ability to provide each individual with teaching practices designed to draw out the full extent of their potential is the crux of socially just teaching. 


\section{Conclusion}

An obvious objection to what we are proposing here is how we will come to implement our executive function model, both as a research task and as teaching and learning practice. We argue that an initial step is to facilitate discussions regarding the learning brain. This includes the development of cross-disciplinary collaborations and dialogues, including, and here we are mindful of intelligence testing's deeply racialised history, with scientists working in fields such as psychobiology, epigenetics, and brain behaviour. We also have to vigilantly remain abreast of what the latest literature across a wide domain of scientific fields is telling us. This would enable the identification of the main principles and factors in the South African context that are influential in outcomes. Additionally, interviews should be conducted with stakeholders in the South African education system, e.g., teachers, parents, learners, training institutions, etc., to explore how these principles and factors are understood as well as to identify knowledge gaps. This will also provide information regarding learner behaviour in the classroom and learners' responses and experiences in relation to different environmental contexts. These engagements will form the foundation of research regarding the impact of environmental factors and experiences on outcomes such as executive function. Furthermore, we have in the studies by Ji and Wang (2018) and Chen et al. (2020), some suggestions for how we might do this. It is anticipated that empirical evidence will ultimately lead to the development of policy as well as evidence-based interventions that are able to develop executive function, and thus resilience and other related mental functions, in learners and caregivers who face adversity.

\section{References}

Alvarez, H. A. O., Appleton, A. A., Fuller, C. H., Belcourt, A., \& Kubzansky, L. D. (2018). An integrated socio-environmental model of health and wellbeing: A conceptual framework exploring the joint contribution of environmental and social exposures to health and disease over the life span. Current Environmental Health Reports, 5, 233 243. https://doi.org/10.1007/s40572-018-0191-2

Anderson, L., \& Krathwohl, D. (Eds.) (2001). A taxonomy for learning, teaching and assessing: A revision of Bloom's taxonomy of educational objectives. Allyn and Bacon.

Anreiter, I., Sokolowski, H. M., \& Sokolowski, M. B. (2017). Gene-environment interplay and individual differences in behavior. Mind, Brain, and Education, 12(4), 200-211.

Ashbury, K., \& Plomin, R. (2014). G is for Genes: The Impact of Genetics on Education and Achievement. John Wiley \& Sons, Inc.

Bradbury, J. (2020). Narrative psychology and Vygotsky in dialogue: Changing subjects. Routledge. 
Brearley, M., \& Hitchfield, E. (1966). A teacher's guide to reading Piaget. Routledge and Kegan Paul.

Brito, N. H., \& Noble, K. G. (2018). The independent and interacting effects of socioeconomic status and dual-language use on brain structure and cognition. Developmental Science, 21(6), e12688. https://doi.org/ 10.1111/desc.12688.

Bueno, D. (2019). Genetics and learning: How the genes influence educational attainment. Frontiers in Psychology, 10, Article 1622.

Bueno, D. (2021). Epigenetics and learning. How the environment shapes gene expression, and the possible consequences for learning and behaviour. Epigenetics. https://solportal.ibe-unesco.org/articles/epigenetics-and-learning-how-theenvironment-shapes-gene-expression-and-the-possible-consequences-for-learningand-behaviour/

Babcock, E. D. (2014). Using brain science to design new pathways out of poverty. Crittenton Women's Union. https://www.empathways.org/researchpolicy/publications/2014-using-brain-science-pathways-out-of-poverty

Center on the Developing Child at Harvard University. (2016). From best practices to breakthrough impacts: A science-based approach to building a more promising future for young children and families. http://www.developingchild.harvard.edu.

Chen, C., Chen, C., Xue, G., Dong, Q., Zhao, L., \& Zhang, S. (2020). Parental warmth interacts with several genes to affect executive function components: A genome-wide environment interaction study. BMC Genetics, 21(11). https://doi.org/10.1186/s12863-020-0819-8

Cortes Pascual, A., Moyano Muñoz, N., \& Quilez Robres, A. (2019). The relationship between executive functions and academic performance in primary education: Review and meta-analysis. Frontiers in Psychology, 10, Article 1582. https://doi.org/10.3389/psyg.2019.01582

Denhardt, D. T. (2017). Effect of stress on human biology: Epigenetics, adaptation, inheritance, and social significance. Journal of Cellular Physiology, 233(3), 19751984. https://doi.org/10.1002/jcp.25837.

Felitti, V., Anda, R. F., Nordenberg, D., Williamson, D. F., Spitz, A. M., Edwards, V., Koss, M. P., \& Marks, J. S. (1998). Relationship of childhood abuse and household dysfunction to many of the leading causes of death in adults: The adverse childhood experiences (ACE) study. American Journal of Preventive Medicine, 14(4), 245-258.

Finders, C. B., Busch-Rossnagel, N. A., Jopp, D. S., \& Brown, J. L. (2012). Applied developmental science, social justice, and socio-political well-being. Applied Developmental Science, 16(1), 54-64. https://doi.org/10.1080/10888691.2012.642786 
Flavell, J. (1977). Cognitive development. Prentice-Hall, Inc.

Fox, S. E., Levitt, P., \& Nelson III, C. A. (2010). How the timing and quality of early experiences influence the development of brain architecture. Child Development, 81(1), 28-40.

Freire, P. (1973). Education for critical consciousness. Continuum.

Frías-Lasserre, D., Villagra, C. A., \& Guerrero-Bosagna, C. (2018). Stress in the educational system as a potential source of epigenetic influences on children's development and behavior. Frontiers in Behavioral Neuroscience, 12(143). https://www.ncbi.nlm.nih.gov/pmc/articles/PMC6053942/

Hill Collins, P. (2019). Intersectionality as Critical Social Theory. Duke University Press.

Ibrahim, O., Sutherland, H. G., Haupt, L. M., \& Griffiths, L. R. (2017). An emerging role for epigenetic factors in relation to executive function. Briefings in Functional Genomics, 17(3), 170-180. https://doi.org/10.1093/bfgp/elx032

Jansen, J., \& O’Ryan, E. (Eds.) (2020). Learning under lockdown. CAN Holdings.

Ji, S., \& Wang, H. (2018). A study of the relationship between adverse childhood experiences, life events, and executive function among college students in China. Psicologia: Reflexão e Crítica, 31(28), 1-9. https://doi.org/10.1186/s41155-0180107-y

Johnson, M. W., Maitland, E., \& Torday, J. (2021). Covid-19 and the epigenetics of learning. Postdigital Science and Education, 3, 389-406. https://doi.org/10.1007/s42438-02000190-9

Knudsen, E. I., Heckman, J. J., Cameron, J. L., \& Shonkoff, J. P. (2006). Economic, neurobiological, and behavioral perspectives on building America's future workforce. Proceedings of the National Academy of Sciences of the United States of America, 103(27), 10155-10162.

Logue, S. F., Gould, T. J. (2014). The neural and genetic basis of executive function: Attention, cognitive flexibility, and response inhibition. Pharmacology Biochemistry and Behavior, 123, 45-54. https://doi.org/10.1016/j.pbb.2013.08.007

Lund, J. I., Toombs, E., Radford, A., Boles, K., \& Mushquash, C. (2020, May 8). Adverse childhood experiences and executive function difficulties in children: A systematic review. Child Abuse \& Neglect, 106, 1-19. [Epub]. https://doi.org/10.1016/j.chiabu.2020.104485

Mansfield, B., \& Guthman, J. (2015). Epigenetic life: Biological plasticity, abnormality, and new configurations of race and reproduction. Cultural Geographies, 22(1), 3-20. 
Meltzer, L. (Ed.). (2007). Executive function in education: From theory to practice. Guilford Press.

Meltzer, L., \& Greschler, M. (2018). Executive function strategies: The building blocks for reading to learn. The Examiner, 7(4) Dyslexiaida.org/executive-function-strategiesthe-building-blocks-for-reading-to-learn/

National Scientific Council on the Developing Child. (2020). Connecting the brain to the rest of the body: Early childhood development and lifelong health are deeply intertwined. Working paper No. 15. www.developingchild.harvard.edu.

Richardson, K., \& Spears, D. (Eds). (1972). Race and intelligence: The fallacies behind the race-IQ controversy. Penguin Books.

Saavedra, J. (2020, March 30). Educational challenges and opportunities of the coronavirus (covid-19) pandemic. Education for Global Development.

https://blogs.worldbank.org/education/educational-challenges-and-opportunitiescovid-19-pandemic.

Shonkoff, J. P. (2010). Building a new biodevelopmental framework to guide the future of early childhood policy. Child Development, 81(1), 357-367.

Shonkoff, J. P., \& Bales, S. N. (2011). Science does not speak for itself: Translating child development research for the public and its policymakers. Child Development, 82(1), 17-32.

Shonkoff, J. P., Garner, A. S., Siegel, B. S., Dobbins, M. I., Earls, M. F., McGuinn, L., Pascoe, J., Wood, D. L., Committee on Psychosocial Aspects of Child and Family Health, Committee on Early Childhood, Adoption, and Dependent Care, \& Section on Developmental and Behavioral Pediatrics. (2012). The lifelong effects of early childhood adversity and toxic stress. Pediatrics, 129, e232-e246. https://doi.org/10.1542/peds.2011-2663

Slade, S. (2020, April 24). How Covid-19 will force education into the future. ASCDInService. Inservice.ascd.org/how-covid-19-will-force-education-into-thefuture/ [Blog].

Soudien, C., \& Harvey, J. (2020). Trouble in our consensus about learning: The politics of learning in the contemporary period. Pedagogy, Culture, and Society, 29(2), 247-261. https://doi.org/10.1080/14681366.2020.1716836

Soudien, C., Harvey, J., \& Juan, A. (forthcoming). Socially just teaching: Teaching to all our differences. In M. Winn \& L. Winn (Eds). Bloomsbury encyclopedia of social justice in education. Bloomsbury Publishing. 
Soudien, C., Reddy, V., \& Harvey, J. (2021). Covid-19 and educational inequality-A political economy of South African education in the wake of a global catastrophe. In F. Reimers (Ed.). Primary and secondary education during Covid-19: Disruptions to educational opportunity during a pandemic (pp. 303-325). Springer.

Tomalski, P., \& Johnson, M. H. (2010). The effects of early adversity on the adult and developing brain. Current Opinion in Psychiatry, 23, 233-238.

The United Nations Educational, Scientific and Cultural Organization. (2020). COVID response website. https://en.unesco.org/covid19/educationresponse.

Wiebe, S. A., Espy, K. A., Stopp, C., Respass, J., Stewart, P., Jameson, T. R., Gilbert, D. G., \& Huggenvik, J. I. (2009). Gene-environment interactions across development: Exploring DRD2 genotype and prenatal smoking effects on self-regulation. Developmental Psychology, 45(1), 31-44.

Zelazo, P. D., \& Müller, U. (2011). Executive function in typical and atypical development. In U. Goswami (Ed.) The Wiley-Blackwell handbook of childhood cognitive development (2nd ed.). John Wiley \& Sons. 